\title{
Simulation Analysis of Additive Manufacturing of Impeller
}

\author{
K. Varsha ${ }^{1}$ and Dr. M. Indira Rani ${ }^{2}$ \\ ${ }^{1}$ PG Scholar, Jawaharlal Nehru Technological University/Mechanical Engg. Hyderabad, India \\ Email: varshayamini970@gmail.com \\ ${ }^{2}$ Professor, Jawaharlal Nehru Technological University/Mechanical Engg. Hyderabad, India \\ Email: marpuindira@gmail.com
}

\begin{abstract}
An Impeller is the rotating component of a pump; it transfers the energy from the motor to the fluid and accelerates the fluid to build up pressure. Impellers are manufactured using Additive Manufacturing (AM) technology. It is a technology that produces three-dimensional parts layer by layer from a variety of materials such as plastics, polymers and metals. The impeller is usually made up of Stainless Steel 316L, Inconel 718. AM technique used to manufacture impeller is Direct Metal Laser Sintering (DMLS). The main objective of this paper is to conduct simulation analysis of additive manufacturing of an impeller by varying process-parameters such as Power, Wall-thickness and Angle and recommend a suitable material with minimum von-misses stress, minimum displacement and minimum of maximum temperature using Amphyon software. Simulation analysis is performed on two different materials i.e., Stainless Steel 316L and Inconel 718 by varying process parameters such as Power at 200 to $400 \mathrm{~W}$, Wall thickness at 0.5 to $0.8 \mathrm{~mm}$ and Angle at $0^{0}$ to $6^{0}$. Amphyon is a modular pre-processing and simulation software for Laser Beam Melting (LBM) processes. The simulation results were analyzed and optimization for Stainless-Steel 316L material impeller was done using one of the MADM methods i.e., Technique for Order of Preference by Similarity to Ideal Solution (TOPSIS) method. Later, the results of the two different materials (i.e., Stainless Steel 316L and Inconel 718) were compared. Stainless Steel $316 \mathrm{~L}$ was found to have minimum von-misses stress, minimum displacement and minimum of maximum temperature at $200 \mathrm{~W}$ power, $0.5 \mathrm{~mm}$ wall-thickness and $0^{0}$ angle.
\end{abstract}

Index Terms: Impeller, Additive Manufacturing, Direct Metal Laser Sintering (DMLS), Amphyon, MADM, TOPSIS.

\section{INTRODUCTION}

Impeller is a rotating element of a centrifugal pump which helps to accelerate the fluid outward from the center of the rotation, thereby transferring energy required from the motor that drives the pump to the motor driven by the fluid $[1,2]$. Various manufacturing techniques are used to build an impeller such as traditional manufacturing (i.e., casting), Additive Manufacturing (i.e., powder bed fusion method) and Hybrid Manufacturing which combines both traditional and additive manufacturing methods that makes it more effective [3]. The Additive manufacturing (AM) or 3D printing techniques have gained immense popularity for its ability to make complex objects such as impeller [4]. It also introduces the possibility for new products, largely due to greater design liberty. AM is a preferred process as it adds material layer by layer thereby reducing the wastage of material when compared to traditional manufacturing which removes the material. AM has a wide range of applications with different variety of materials such as plastics, polymers and metals [5]. The impeller is usually made of Stainless Steel $316 \mathrm{~L}$ and Inconel 718 as both these materials have high corrosion resistance. Both these materials are anisotropic in nature i.e., they show different behaviour along the different directions of the materials. It has been observed that the maximum anisotropic deformation is found at 450 for both the materials [6,7]. The AM method used to manufacture metal products is Laser Power Bed Fusion method. One of the LPBF technique used to manufacture impeller is Direct Metal Laser Sintering (DMLS) $[8,9,10,11,12]$ as it has a wide range of materials such as Stainless steel 3161, Inconel718, Ti6A14V, Stainless steel 17-PH. The principle behind this method is the application of thin layers of metal powder using a re-coater blade. The metal powder is sintered by a collimated laser beam, which fuses the particles of the metal together to create a solid material. The main objective of this paper is to conduct a simulation analysis of additive manufacturing of an impeller and to recommend a suitable material for manufacturing with minimum Von-misses stress, minimum Displacement and minimum of maximum Temperature by varying various process-parameters such as Power (200W to $400 \mathrm{~W})$, Wall-thickness $(0.5 \mathrm{~mm}$ to $0.8 \mathrm{~mm})$ and Angle $\left(0^{0}\right.$ to $6^{0}$ ) using Amphyon software. Amphyon is a modular preprocessing and simulation software for Laser Beam Melting (LBM) processes. The values of power, wall-thickness and angles are considered based on the following recommendations. The wall thickness above $0.5 \mathrm{~mm}$ is considered to avoid warpage in the components $[13,14]$. The power impacts the micro-structure of the material thus two different laser powers are being considered [15] and according to the Amphyon software simulation assessment these orientations angles (i.e., $0^{0}$ to $6^{0}$ ) with respect to build plate was recommended for the material and build conditions mentioned earlier. Based on the above build parameters EOSINT M280 machine is considered for simulation. The simulation values were recorded. The simulation results of stainless steel were analyzed and optimization was performed using one of the Multi Attribute Decision Making (MADM). The technique used to perform optimization was Technique for Order of Preference by Similarity to Ideal Solution (TOPSIS) [16]. 


\section{Materials and Machine Specification}

\section{A. Materials}

The materials used to manufacture impeller are Stainless Steel $316 \mathrm{~L}$ and Inconel 718 as they have high corrosion resistance.

Stainless Steel: The composition and mechanical properties are shown in Table I and Table II.

\section{Material properties:}

1. High hardness and toughness.

2. High corrosion resistance.

3. High machine-ability.

4. Can be highly polished.

TABLE I

PROPERTIES OF STAINLESS STEEL 316L

\begin{tabular}{|c|c|}
\hline Property & Value \\
\hline Ultimate tensile Strength & $1467 \mathrm{MPa}$ \\
\hline Yield Stress & $1150 \mathrm{MPa}$ \\
\hline Young's modulus & $205 \mathrm{GPa}$ \\
\hline Poisson's ratio & 0.3 \\
\hline
\end{tabular}

TABLE II.

COMPOSITION OF STAINLESS STEEL 316L

\begin{tabular}{|c|c|}
\hline Element & Concentration [Wt.\%] Acc. ASTM A276 \\
\hline Carbon & $\leq 0.03$ \\
\hline Manganese & $\leq 2$ \\
\hline Silicon & $\leq 1$ \\
\hline Nitrogen & $\leq 0.1$ \\
\hline Phosphorous & $\leq 0.045$ \\
\hline Sulphur & $\leq 0.015$ \\
\hline Molybdenum & $2-3$ \\
\hline Chromium & $16-18$ \\
\hline Nickel & $10-14$ \\
\hline Iron & Balance \\
\hline Manganese & $\leq 0.03$ \\
\hline
\end{tabular}

Inconel 718: The composition and mechanical properties are shown in Table III and Table IV.

Material properties:

1. Retains strength up to $650{ }^{\circ} \mathrm{C}$.

2. High creep resistance.

3. High corrosion resistance.

4. Solidification properties suit additive manufacture.
TABLE III.

COMPOSITION OF INCONEL 718

\begin{tabular}{|c|c|}
\hline Element & Mass $(\%)$ \\
\hline Nickel & $50-55$ \\
\hline Chromium & $17-21$ \\
\hline Niobium and tantalum & $4.75-5.5$ \\
\hline Molybdenum & $2.80-3.30$ \\
\hline Titanium & $0.65-1.15$ \\
\hline Cobalt & $\leq 1.00$ \\
\hline Aluminum & $0.20-0.80$ \\
\hline Manganese & $\leq 0.35$ \\
\hline Silicon & $\leq 0.35$ \\
\hline Copper & $\leq 0.30$ \\
\hline Carbon & $0.02-0.05$ \\
\hline Nitrogen & $\leq 0.03$ \\
\hline Oxygen & $\leq 0.03$ \\
\hline Phosphorous & $\leq 0.015$ \\
\hline Sulphur & $\leq 0.015$ \\
\hline Calcium & $\leq 0.01$ \\
\hline Magnesium & $\leq 0.01$ \\
\hline Selenium & $\leq 0.005$ \\
\hline Boron & $\leq 0.005$ \\
\hline Iron & Balance \\
\hline
\end{tabular}

TABLE IV

MECHANICAL PROPERTIES OF INCONEL 718

\begin{tabular}{|c|c|}
\hline Property & Value \\
\hline Ultimate tensile Strength & $676 \mathrm{MPa}$ \\
\hline Yield Stress & $541 \mathrm{MPa}$ \\
\hline Young's modulus & $178 \mathrm{GPa}$ \\
\hline Poisson's ratio & 0.3 \\
\hline
\end{tabular}

\section{B. Machine Specifications}

The machine used is EOSINT M 280. The machine comprises a process chamber with recoating system, elevating system and platform heating module, an optical system with laser, a process gas management system, a process computer with process control software, and a set of standard accessories. The machine components are integrated into a robust machine frame. During operation the process chamber is secured by interlock. The specifications are shown in the Table $\mathrm{V}$. 
TABLE V.

EOSINT M 280 MACHINE TECHNICAL DATA

\begin{tabular}{|c|c|}
\hline Effective building volume & $250 \mathrm{~mm} \times 250 \mathrm{~mm} \times 215 \mathrm{~mm}$ \\
\hline $\begin{array}{l}\text { Building speed (material- } \\
\text { dependent) }\end{array}$ & $\begin{array}{c}2-20 \mathrm{~mm} 3 / \mathrm{s}(0.0001-0.001 \\
\text { in } 3 / \mathrm{sec})\end{array}$ \\
\hline Laser Power & $200 \mathrm{~W}$ or $400 \mathrm{~W}$ \\
\hline Laser Type & $\mathrm{Yb}$-fiber laser \\
\hline Scan Speed & Up to $7.0 \mathrm{~m} / \mathrm{s}$ \\
\hline Power Supply & $32 \mathrm{~A}$ \\
\hline Layer Thickness & $20-60 \mu \mathrm{m}$ \\
\hline Power Consumption & Max $8.5 \mathrm{~kW} /$ typical $3.2 \mathrm{~kW}$ \\
\hline Precision Optics & $\begin{array}{l}\text { F-theta- lens, high- speed } \\
\text { scanner }\end{array}$ \\
\hline Variable focus diameter & $100-500 \mu \mathrm{m}$ \\
\hline Nitrogen generator & Standard \\
\hline \multicolumn{2}{|c|}{ Dimensions: } \\
\hline System & $2000 \mathrm{~mm} \times 1050 \mathrm{~mm} \times 1940 \mathrm{~mm}$ \\
\hline $\begin{array}{l}\text { Recommended installation } \\
\text { space }\end{array}$ & Approx. $3.5 \mathrm{~m} \times 3.6 \mathrm{~m} \times 2.5 \mathrm{~m}$ \\
\hline Weight & Approx. $1130 \mathrm{~kg}$ \\
\hline
\end{tabular}

\section{Amphyon Software}

Amphyon is a modular pre-processing and simulation software for laser beam melting (LBM) processes. The Amphyon modules can be used in pre-processing chains from CAD to build job by replacing or improving several stages. Driven by industrial needs and requirements in LBM processes, an innovative new pre-process chain was derived. Three main stages on the way to a stable, efficient and reliable process were identified.

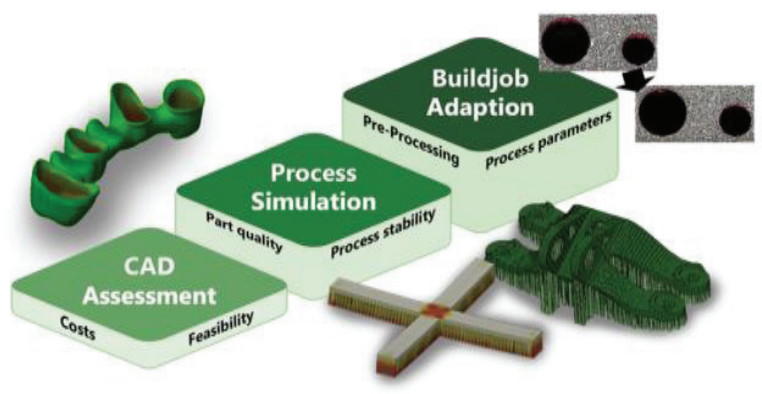

Figure 1. The ASAP Principle

The mechanical simulation model in Amphyon uses an approach called Inherent Strain approach. The basic principle of the inherent strain approach for additive manufacturing is that if no external loads are applied, the inherent strains is defined as the sum of plastic and thermal strains which completely defines the stress state and the deformation within a given domain. The inherent strain approach for additive manufacturing is also called Mechanical Layer Equivalent (MLE) Method.

The thermal simulation model in Amphyon uses an approach of Global Thermal Analysis. The build rate and the amount of time for cooling down between consecutive layers is one of the most important influencing factors for the macro scale thermal simulation of the process. If the cool down time between layers is increases by a factor of two, the macro scale thermal field is reduced by approximately the same factor if non-linear influences such as radiation, convection, absorption etc. are neglected.

\section{Methodology}

The steps involved in the simulation analysis is shown in the Figure 2. Twelve different simulation analysis are done for each material by varying the power $(200 \mathrm{~W}, 400 \mathrm{~W})$, wall-thickness $(0.5 \mathrm{~mm}, 0.8 \mathrm{~mm})$ and angle $\left(0^{0}, 2^{0}, 5^{0}\right)$ respectively. The impellers with different angles with respect to build plate and their supports are shown in the Figure 3.

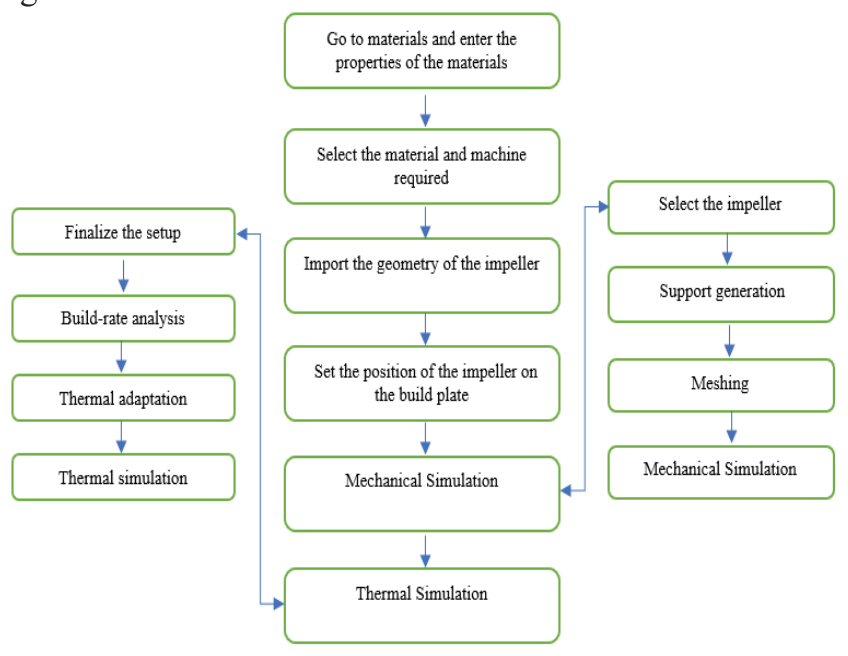

Figure 2. Flow-chart of steps involved in Simulation process

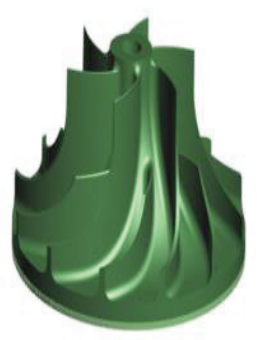

(a)

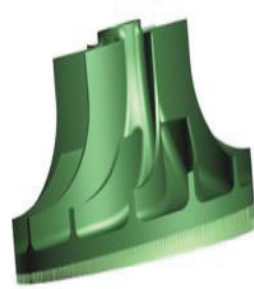

(b)

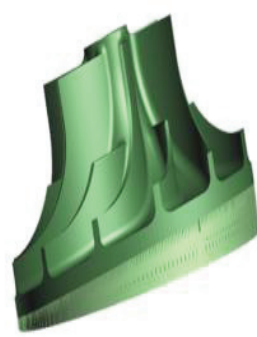

(c)
Figure 3. Supports generated to impeller build at different angles w.r.t build plate. (a) $0^{0}$ angle (b) $2^{0}$ angle (c) $5^{0}$ angle

\section{E. Boundary conditions}

\section{Mechanical simulations:}

- Material is anisotropic, max deformation at $45^{\circ}$.

- Heat treatment: After the release of the base, stresses to zero

Thermal simulations:

- $\quad$ Preheating of the build area at $50^{\circ} \mathrm{C}$.

- Energy transferred into the part.

- Evaporation the material

- Convection on the outside surface of Heat affected zone. 


\section{RESULTS}

The results of the simulation are shown in the Table VI and Table VII. The tables consist of the values of vonmisses stress, displacement and maximum temperature of Stainless steel 316L and Inconel 718.

TABLE VI

VALUES OF INCONEL 718

\begin{tabular}{|c|c|c|c|c|c|}
\hline $\begin{array}{c}\text { Power } \\
(\mathrm{W})\end{array}$ & $\begin{array}{c}\text { Wall } \\
\text { Thickness } \\
(\mathrm{mm})\end{array}$ & Angle & $\begin{array}{c}\text { Von-Misses } \\
(\mathrm{MPA})\end{array}$ & $\begin{array}{c}\text { Max } \\
\text { Temperature } \\
(\mathrm{C})\end{array}$ & $\begin{array}{c}\text { Displace } \\
\text { ment } \\
(\mathrm{mm})\end{array}$ \\
\hline 200 & 0.5 & 0 & 0.118 & 59.504 & 0.245 \\
\hline 200 & 0.5 & 2 & 0.7448 & 59.74 & 0.288 \\
\hline 200 & 0.5 & 5 & 0.303 & 62.328 & 0.370 \\
\hline 200 & 0.8 & 0 & 0.1669 & 59.560 & 0.300 \\
\hline 200 & 0.8 & 2 & 0.190136 & 59.649 & 0.337 \\
\hline 200 & 0.8 & 5 & 0.600 & 67.9 & 0.439 \\
\hline 400 & 0.5 & 0 & 0.1539 & 69.23 & 0.246 \\
\hline 400 & 0.5 & 2 & 0.5120 & 69.97 & 0.285 \\
\hline 400 & 0.5 & 5 & 0.555 & 75.15 & 0.369 \\
\hline 400 & 0.8 & 0 & 0.1948 & 69.468 & 0.300 \\
\hline 400 & 0.8 & 2 & 0.3127 & 69.656 & 0.335 \\
\hline 400 & 0.8 & 5 & 0.53029 & 86.12 & 0.438 \\
\hline
\end{tabular}

TABLE VII.

VALUES OF STAINLESS STEEL 316L

\begin{tabular}{|c|c|c|c|c|c|}
\hline $\begin{array}{c}\text { Power } \\
(\mathrm{W})\end{array}$ & $\begin{array}{c}\text { Wall } \\
\text { Thickness } \\
(\mathrm{mm})\end{array}$ & Angle & $\begin{array}{c}\text { Von- } \\
\text { Misses } \\
(\mathrm{MPa})\end{array}$ & $\begin{array}{c}\text { Max } \\
\text { Temperature } \\
(\mathrm{C})\end{array}$ & $\begin{array}{c}\text { Displacem } \\
\text { ent (mm) }\end{array}$ \\
\hline 200 & 0.5 & 0 & 0.118 & 59.504 & 0.245 \\
\hline 200 & 0.5 & 2 & 0.7448 & 59.74 & 0.288 \\
\hline 200 & 0.5 & 5 & 0.303 & 62.328 & 0.370 \\
\hline 200 & 0.8 & 0 & 0.1669 & 59.560 & 0.300 \\
\hline 200 & 0.8 & 2 & 0.190136 & 59.649 & 0.337 \\
\hline 200 & 0.8 & 5 & 0.600 & 67.9 & 0.439 \\
\hline 400 & 0.5 & 0 & 0.1539 & 69.23 & 0.246 \\
\hline 400 & 0.5 & 2 & 0.5120 & 69.97 & 0.285 \\
\hline 400 & 0.5 & 5 & 0.555 & 75.15 & 0.369 \\
\hline 400 & 0.8 & 0 & 0.4912 & 69.05 & 0.269 \\
\hline 400 & 0.8 & 2 & 0.4589 & 69.226 & 0.322 \\
\hline 400 & 0.8 & 5 & 0.3039 & 85.644 & 0.412 \\
\hline
\end{tabular}

Optimization: Table VIII shows minimum stress and displacement at $200 \mathrm{~W}, 0^{0}$ and $0.5 \mathrm{~mm}$ wall-thickness and minimum value of maximum temperature occurs at $200 \mathrm{~W}$, $5^{0}$ and $0.5 \mathrm{~mm}$ wall-thickness. To resolve this ambiguity, one of the MADM techniques i.e., Technique for Order of Preference by Similarity to Ideal Solution (TOPSIS) is used. The process is carried out as follows:

Step 1: Create an evaluation matrix
TABLE VIII.

DECISION TABLE

\begin{tabular}{|c|c|c|c|c|c|}
\hline & & \multicolumn{3}{|c|}{ Beneficial } \\
\hline $\begin{array}{c}\text { Power } \\
(\mathrm{W})\end{array}$ & $\begin{array}{c}\text { Wall } \\
\text { Thickness } \\
(\mathrm{mm})\end{array}$ & Angle & $\begin{array}{c}\text { Von-Misses } \\
(\mathrm{MPa})\end{array}$ & $\begin{array}{c}\text { Max } \\
\text { Temperature } \\
\left({ }^{\circ} \mathrm{C}\right)\end{array}$ & $\begin{array}{c}\text { Displacem } \\
\text { ent (mm) }\end{array}$ \\
\hline 200 & 0.5 & 0 & 0.071665 & 58.1 & 0.189 \\
\hline 200 & 0.5 & 2 & 0.2580 & 57.17 & 0.241 \\
\hline 200 & 0.5 & 5 & 0.156 & 47.4 & 0.343 \\
\hline 200 & 0.8 & 0 & 0.114 & 59.40 & 0.266 \\
\hline 200 & 0.8 & 2 & 0.209 & 59.75 & 0.323 \\
\hline 200 & 0.8 & 5 & 0.546 & 53 & 0.411 \\
\hline 400 & 0.5 & 0 & 0.0729 & 69.206 & 0.1905 \\
\hline 400 & 0.5 & 2 & 0.4089 & 69.59 & 0.242 \\
\hline 400 & 0.5 & 5 & 0.2058 & 75.71 & 0.3427 \\
\hline 400 & 0.8 & 0 & 0.4912 & 69.05 & 0.269 \\
\hline 400 & 0.8 & 2 & 0.4589 & 69.226 & 0.322 \\
\hline 400 & 0.8 & 5 & 0.3039 & 85.644 & 0.412 \\
\hline
\end{tabular}

Step 2: Obtain normalized decision matrix $\mathrm{X}_{\mathrm{ij}}{ }^{*}=\frac{\mathrm{Xij}}{\sqrt{\sum \mathrm{Xi}^{2}}}$

TABLE IX.

VALUES OF $\mathrm{Xi}^{2} \mathrm{AND} \sqrt{\sum \mathrm{Xi}^{2}}$

\begin{tabular}{|c|c|c|c|}
\hline $\mathrm{Xi}^{2}$ & 1.20991799 & 51057.4803 & 1.11354354 \\
\hline $\operatorname{SQRT}\left(\sum \mathrm{Xi}^{2}\right)$ & 1.09996272 & 225.959024 & 1.05524572 \\
\hline
\end{tabular}

TABLE X. NORMALIZED TABLE

\begin{tabular}{|c|c|c|c|c|c|}
\hline $\begin{array}{c}\text { Power } \\
(\mathrm{W})\end{array}$ & $\begin{array}{c}\text { Wall } \\
\text { Thickness } \\
(\mathrm{mm})\end{array}$ & Angle & $\begin{array}{c}\text { Von-Misses } \\
(\mathrm{MPa})\end{array}$ & $\begin{array}{c}\text { Max } \\
\text { Temperatur } \\
\mathrm{e}\left({ }^{\circ} \mathrm{C}\right)\end{array}$ & $\begin{array}{c}\text { Displacement } \\
(\mathrm{mm})\end{array}$ \\
\hline 200 & 0.5 & 0 & 0.0051358 & 3375.61 & 0.035721 \\
\hline 200 & 0.5 & 2 & 0.066564 & 3268.4089 & 0.058081 \\
\hline 200 & 0.5 & 5 & 0.024336 & 2246.76 & 0.117649 \\
\hline 200 & 0.8 & 0 & 0.012996 & 3528.36 & 0.070756 \\
\hline 200 & 0.8 & 2 & 0.043681 & 3570.0625 & 0.104329 \\
\hline 200 & 0.8 & 5 & 0.298116 & 2809 & 0.168921 \\
\hline 400 & 0.5 & 0 & 0.0053144 & 4789.4704 & 0.03629025 \\
\hline 400 & 0.5 & 2 & 0.1671992 & 4842.7681 & 0.058564 \\
\hline 400 & 0.5 & 5 & 0.0423536 & 5732.0041 & 0.11744329 \\
\hline 400 & 0.8 & 0 & 0.2412774 & 4767.9025 & 0.072361 \\
\hline 400 & 0.8 & 2 & 0.2105892 & 4792.2390 & 0.103684 \\
\hline 400 & 0.8 & 5 & 0.0923552 & 7334.8947 & 0.169744 \\
\hline
\end{tabular}


Step 3: Calculate the weighted normalized decision matrix TABLE XI.

CALCULATION OF WEIGHTS

\begin{tabular}{|c|c|c|c|c|}
\hline S. No. & & $\begin{array}{c}\text { Von-Misses } \\
(\mathrm{MPa})\end{array}$ & $\begin{array}{c}\text { Max } \\
\text { Temperature } \\
\left({ }^{\circ} \mathrm{C}\right)\end{array}$ & $\begin{array}{c}\text { Displacement } \\
(\mathrm{mm})\end{array}$ \\
\hline & Weights & 0.33 & 0.33 & 0.33 \\
\hline 1 & & 0.06515221 & 0.25712627 & 0.1791052 \\
\hline 2 & & 0.2345534 & 0.25301048 & 0.22838283 \\
\hline 3 & & 0.14182299 & 0.20977255 & 0.32504278 \\
\hline 4 & & 0.10363988 & 0.26287952 & 0.25207399 \\
\hline 5 & & 0.19000644 & 0.26442847 & 0.30608984 \\
\hline 6 & & 0.49638046 & 0.2345558 & 0.38948274 \\
\hline 7 & & 0.06627497 & 0.30627677 & 0.18052667 \\
\hline 8 & & 0.37173987 & 0.30797619 & 0.22933047 \\
\hline 9 & & 0.18709725 & 0.33506075 & 0.32475848 \\
\hline 10 & & 0.44656059 & 0.30558638 & 0.25491693 \\
\hline 11 & & 0.41719596 & 0.30636528 & 0.3051422 \\
\hline 12 & & 0.27628209 & 0.37902447 & 0.39043039 \\
\hline
\end{tabular}

TABLE XII.

NORMALIZED WEIGHT TABLE

\begin{tabular}{|c|c|c|c|}
\hline S. No. & $\begin{array}{c}\text { Von-Misses } \\
(\mathrm{MPa})\end{array}$ & $\begin{array}{c}\text { Max Temperature } \\
\left({ }^{\circ} \mathrm{C}\right)\end{array}$ & $\begin{array}{c}\text { Displacement } \\
(\mathrm{mm})\end{array}$ \\
\hline 1 & 0.02169569 & 0.08485167 & 0.05910472 \\
\hline 2 & 0.07810628 & 0.08349346 & 0.07536633 \\
\hline 3 & 0.04722705 & 0.06922494 & 0.10726412 \\
\hline 4 & 0.03451208 & 0.08675024 & 0.08318442 \\
\hline 5 & 0.06327214 & 0.0872614 & 0.10100965 \\
\hline 6 & 0.16529469 & 0.07740341 & 0.12852931 \\
\hline 7 & 0.02206957 & 0.10107133 & 0.0595738 \\
\hline 8 & 0.12378938 & 0.10163214 & 0.07567906 \\
\hline 9 & 0.06230338 & 0.11057005 & 0.1071703 \\
\hline 10 & 0.14870468 & 0.10084351 & 0.08412259 \\
\hline 11 & 0.13892625 & 0.10110054 & 0.10069693 \\
\hline 12 & 0.09200194 & 0.12507808 & 0.12884203 \\
\hline
\end{tabular}

Step 4: Determine the worst and the best alternative.

TABLE XIII

VALUES OF $\mathrm{V}^{+}$and $\mathrm{V}^{-}$

\begin{tabular}{|c|c|c|c|c|}
\hline $\mathrm{V}^{+}$ & 0.02169569 & 0.06922494 & 0.05910472 & $\mathrm{~V}^{+}$ \\
\hline $\mathrm{V}^{-}$ & 0.16529469 & 0.12507808 & 0.12884203 & $\mathrm{~V}^{-}$ \\
\hline
\end{tabular}

Step 5: Calculate Separation Measures

$$
(S)^{+}=\sqrt{\sum_{j=1}^{m}\left(V_{i j}-V^{+}\right)^{2}} \quad(S)^{-}=\sqrt{\sum_{j=1}^{m}\left(V_{i j}-V^{-}\right)^{2}}
$$

TABLE XIV.

NORMALIZED WEIGHT TABLE

\begin{tabular}{|c|c|c|}
\hline S. No. & $\mathrm{S}^{+}$ & $\mathrm{S}^{-}$ \\
\hline 1 & 0.015627 & 0.164627 \\
\hline 2 & 0.060417 & 0.110412 \\
\hline 3 & 0.054509 & 0.132383 \\
\hline 4 & 0.032423 & 0.143728 \\
\hline 5 & 0.061725 & 0.112309 \\
\hline 6 & 0.15971 & 0.047676 \\
\hline 7 & 0.031852 & 0.160897 \\
\hline 8 & 0.108388 & 0.071405 \\
\hline 9 & 0.075291 & 0.106242 \\
\hline 10 & 0.133255 & 0.053501 \\
\hline 11 & 0.128409 & 0.045413 \\
\hline 12 & 0.113692 & 0.073293 \\
\hline
\end{tabular}

Step 6: Calculate relative closeness to positive ideal solution $\mathrm{Pi}=\frac{s^{-}}{s^{-}+s^{+}}$and rank them

TABLE XV

RANK TABLE

\begin{tabular}{|c|c|c|}
\hline$S^{-}+S^{+}$ & $\mathrm{P}_{\mathrm{i}}$ & Rank \\
\hline 0.180254 & 0.913307 & 1 \\
\hline 0.170828 & 0.646331 & 5 \\
\hline 0.186891 & 0.708341 & 4 \\
\hline 0.176151 & 0.815938 & 3 \\
\hline 0.174034 & 0.645329 & 6 \\
\hline 0.207386 & 0.229889 & 12 \\
\hline 0.192749 & 0.834749 & 2 \\
\hline 0.179794 & 0.397151 & 8 \\
\hline 0.181533 & 0.58525 & 7 \\
\hline 0.186756 & 0.286476 & 10 \\
\hline 0.173823 & 0.261262 & 11 \\
\hline 0.186985 & 0.391972 & 9 \\
\hline
\end{tabular}

From the above table we can conclude that the best optimal result is found at $200 \mathrm{~W}, 0^{0}$ angle and $0.5 \mathrm{~mm}$ wallthickness. 
Comparison of Stainless steel 316L and Inconel 718: Fig.4, Fig. 5 and Fig.6 shows the comparison of the materials drawn from the results obtained.

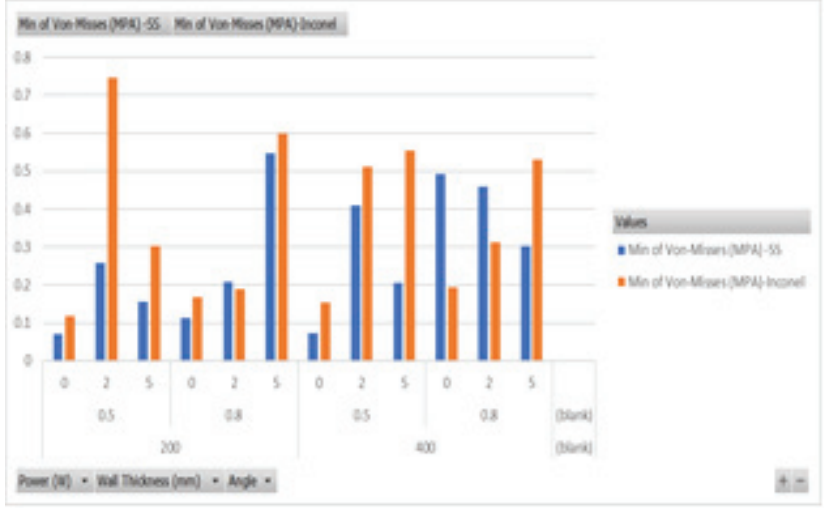

Figure 4. Variation of von-misses stress w.r.t Power, angle and wallthickness

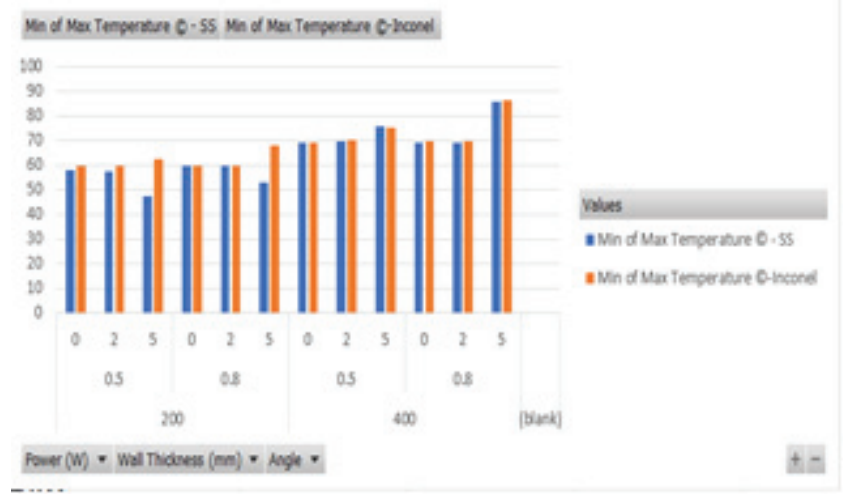

Figure 5. Variation of Maximum temperature w.r.t Power, angle and wallthickness

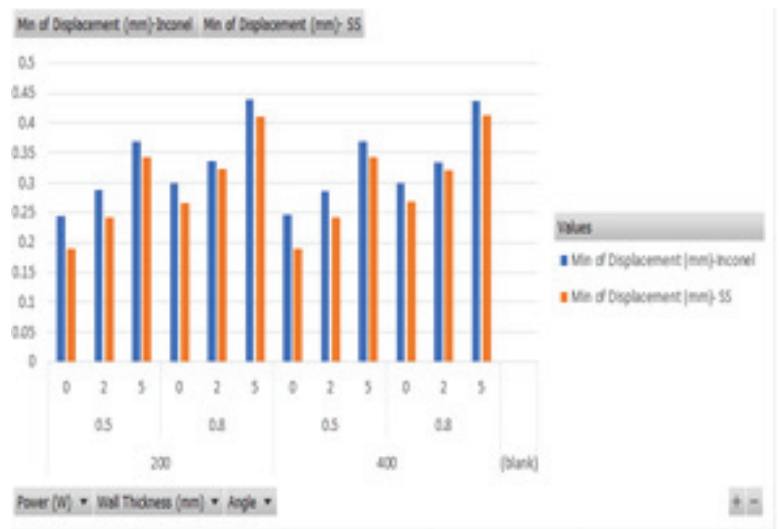

Figure 6. Variation of Displacement w.r.t Power, angle and wall-thickness

\section{Discussion}

The minimum stress and minimum displacement occur at 200W, $0^{0}$ and $0.5 \mathrm{~mm}$ wall-thickness and minimum of max temperature occurs at $200 \mathrm{~W}, 5^{0}$ and $0.5 \mathrm{~mm}$ wall-thickness. To resolve this ambiguity, one of the MADM technique i.e., Technique for Order of Preference by Similarity to Ideal Solution (TOPSIS) is used. As result, it was found that optimal value occurs at $200 \mathrm{~W}, 0^{0}$ and $0.5 \mathrm{~mm}$ wall-thickness. Later, the graphs are plotted between both the materials to find out which material gives better results. It is observed that Stainless Steel $316 \mathrm{~L}$ at $200 \mathrm{~W}, 0^{0}$ and $0.5 \mathrm{~mm}$ wallthickness gives us better results.

\section{CONCLUSIONS}

From the present study the following conclusions can be drawn:

1. Stainless steel $316 \mathrm{~L}$ and Inconel 718 are selected for manufacturing the impeller is because both the materials have high corrosion resistance.

2. Amphyon software gives us the mechanical and thermal results using inherent strain method and thermal global analysis method respectively.

3. The minimum Von-misses stress, minimum Displacement and minimum of max Temperature are recommended to avoid failure in the supports and workpiece.

4. Based on the simulation results of Stainless steel 3161, the minimum stress and minimum displacement occurs at $200 \mathrm{~W}, 0^{0}$ and $0.5 \mathrm{~mm}$ wall-thickness and minimum of max temperature occurs at $200 \mathrm{~W}, 5^{0}$ and $0.5 \mathrm{~mm}$ wallthickness. To resolve this optimization is done using TOPSIS technique and best result was obtained at $200 \mathrm{~W}, 0^{0}$ and $0.5 \mathrm{~mm}$ wall-thickness.

5. Finally, when the results of both the materials were compared, Stainless steel $316 \mathrm{~L}$ at $200 \mathrm{~W}, 0^{0}$ and $0.5 \mathrm{~mm}$ wall-thickness had minimum von-misses stress, displacement and minimum of max temperature. Thus, the material recommended is stainless steel $316 \mathrm{~L}$.

\section{REFERENCES}

[1] Farah Elida SELAMAT, Wan Hariz Iskandar WAN IZHAN, Bakhtiar Saffuan BAHARUDIN, "Design and Analysis of Centrifugal Pump Impeller for Performance Enhancement", 2018.

[2] Michail D. Mentzos, Angelos P. Markopoulos, Nikolaos I. Galanis, Dionissios P. Margaris, Dimitrios E. Manolakos, "Design, Numerical Analysis and Manufacture of Radial Pump Impellers with Various Blade Geometries", 2015.

[3] Scot Laney, Derrick Bauer, Akiyoshi Ando, "Evaluation of various methods for manufacturing one-piece, small tip opening centrifugal compressor impellers", February 2016.

[4] Alexandra Adiaconitei, Ionut Sebastian Vintila, Radu Mihalache, Alexandru Paraschiv, Tiberius Frigioescu, Mihai Vladut, and Laurent Pambaguian, "A Study on Using the Additive Manufacturing Process for the Development of a Closed Pump Impeller for Mechanically Pumped Fluid Loop Systems", February 2021.

[5] Thomas Mayer, Gabriel Br€andle, Andreas Schonenberger, Robert Eberlein, "Simulation and validation of residual deformations in additive manufacturing of metal parts", May 2020.

[6] Leonhard Hitzler, Johann Hirsch, Burkhard Heine, Markus Merkel, Wayne Hall, and Andreas Öchsner, "Anisotropic Mechanical Properties of Selective Laser Melted Stainless Steel", 2017.

[7] Even W. Hovig, Amin S. Azar, Frode Grytten, Knut Sørby, and Erik Andreassen, "Determination of Anisotropic Mechanical Properties for Materials Processed by Laser Powder Bed Fusion", November 2018. 
[8] Peiying Bian, Xiaodong Shao, and Jingli Du, "Finite Element Analysis of Thermal Stress and Thermal Deformation in Typical Part during SLM", 28 May 2019.

[9] Kai Zhan, Tingting Liu, Wenhe Liao, Changdong Zhang, Yi Zheng, Huang Shao, "Simulation of The Thermal Behaviour and Analysis of Solidification Process During Selective Laser Melting of Alumina", 2018.

[10] C. Y. Yap, C. K. Chua, Z. L. Dong, Z. H. Liu, D. Q. Zhang, L. E. Loh, and S. L. Sing, "Review of selective laser melting: Materials and applications", 2015.

[11] Röttger, J. Boes, W. Theisen, M. Thiele, C. Esen, A. Edelmann, and R. Hellmann, "Microstructure and mechanical properties of $316 \mathrm{~L}$ austenitic stainless steel processed by different SLM devices", 30 September 2019.

[12] Milan Daňa, Ivana Zetková, and Josef Mach, "Mechanical Properties of Inconel Alloy 718 Produced by 3D Printing using DMLS", September 2018.

[13] Johanna timhagen daniel nalumm, "Study of wall thickness and its impact on microstructure on 316L manufactured with Direct Metal Laser Sintering", 2017.

[14] "Guidelines for Wall Thickness in Laser Sintering: Guidelines for Wall Thickness in Laser Sintering" | Additive Manufacturing [Accessed on February 2021].

[15] Hahn Choo, Kin-Ling Sham, John Bohling, Austin Ngo, Xianghui Xiao, Yang Renb, Philip J. Depond, Manyalibo J. Matthews, Elena Garlea, "Effect of laser power on defect, texture, and microstructure of a laser powder bed fusion processed 316L stainless steel”, 2018.

[16] Ali Jozaghi, Babak Alizadeh, Mohsen Hatami, Ian Flood, Mohammad Khorrami, Nastaran Khodaei, and Erfan Ghasemi Tousi, "A Comparative Study of the AHP and TOPSIS Techniques for Dam Site Selection Using GIS: A Case Study of Sistan and Baluchestan Province, Iran", December 2018

[17] Paul Swartz, "Evaluation of Tensile Properties for Selective Laser Melted 3161 Stainless Steel and The Influence of Inherent Process Features on Static Performance", June 2019.
[18] K. Kamarudin, M.S Wahab, A.A. Raus, Aqeel Ahmed, and S Shamsudin, "Benchmarking of Dimensional Accuracy and Surface Roughness for AlSi10Mg Part by Selective Laser Melting (SLM)", 2017.

[19] Altaf Ahmed, Arfan Majeed, Zahid Atta, and Guozhu Jia, "Dimensional Quality and Distortion Analysis of ThinWalled Alloy Parts of AlSi10Mg Manufactured by Selective Laser Melting", 2019.

[20] Nils Keller, John Schlasche, Hongxiao $\mathrm{Xu}$, and Vasily Ploshikhin, Simulation Aided Manufacturing Scanning Strategies for Low Distortion in Laser Beam Melting Processes", 2016.

[21] Elham Mirkoohi, Hong-Chuong Tran, Yu-Lung Lo, YouCheng Chang, Hung-Yu Lin, and Steven Y. Liang, "Analytical Modeling of Residual Stress in Laser Powder Bed Fusion Considering Part's Boundary Condition", April 2020.

[22] Tae-Jun Kim, Beom-Seon Jang, and Sung-Wook Kang, "Welding deformation analysis based on improved equivalent strain method considering the effect of temperature gradients", 2015.

[23] Thoufeili Taufek, Yupiter HP Manurung, Stephan Lüder, Marcel Graf, and Farrahshaida Mohd Salleh, "Distortion Analysis of SLM Product of SS316L using Inherent Strain Method", 2019

[24] Suvi Santa-aho, Mika Kiviluoma, Tuomas Jokiaho, Tejas Gundgire, Mari Honkanen, Mari Lindgren, and Minnamari Vippola, "Additive Manufactured 316L Stainless-Steel Samples: Microstructure, Residual Stress and Corrosion Characteristics after Post-Processing", January 2021.

[25] Santosh Kumar Parupelli, and Salil Desai, "A Comprehensive Review of Additive Manufacturing (3D Printing): Processes, Applications and Future Potential, 2019.

[26] "A Review on Direct Metal Laser Sintering: Process Features and Microstructure Modeling", Available from: https://www.researchgate.net/publication/334504563_A_Rev iew on Direct Metal Laser Sintering Process Features an d_Microstructure_Modeling [accessed Feb 26 2021] 